\title{
Developing Rainfall Intensity Duration Curve for Selected Towns in Western Part of Ethiopia
}

\author{
Jemal Ibrahim Mohammed*, Getachew Rabo Kumsa \\ Hydraulic and Water Resources Engineering, College of Engineering and Technology, Wollega University, Nekemte, Ethiopia
}

Email address:

ijemal2004@gmail.com (J. I. Mohammed)

${ }^{*}$ Corresponding author

To cite this article:

Jemal Ibrahim Mohammed, Getachew Rabo Kumsa. Developing Rainfall Intensity Duration Curve for Selected Towns in Western Part of Ethiopia. Hydrology. Vol. 9, No. 3, 2021, pp. 56-65. doi: 10.11648/j.hyd.20210903.11

Received: May 3, 2021; Accepted: June 24, 2021; Published: August 2, 2021

\begin{abstract}
Rainfall and Its Intensity is needed for planning and designing of various water resource projects including infrastructure such as the design of urban drainage works, Storm Sewers, Culverts and etc. The main aim of this research was to develop Rainfall intensity duration curve for the selected towns in western part of Ethiopia. Gumbel and the Log Pearson Type III Probability distribution (LPT III) were used to develop rainfall intensity duration curves for the selected towns in western part of Ethiopia. The IDF curves developed by Gumbel's Extreme value distribution shows, the pattern similarity for all return period, duration and all considered stations but the rainfall intensity shows an increasing with increase in the return period and decrease with rainfall duration increase in all return periods and also show high Rainfall intensity ( $\mathrm{mm} / \mathrm{hr}$.) so that it was used to derive Empirical equation using Logarithmic transformation method to determine the constants $(\mathrm{C}, \mathrm{m}, \mathrm{a})$ considered to derive the equation. Then the comparison was made between rainfall developed by using Gamble's Probability distribution and computed by Empirical equation. In all return period and duration of time it shows good relation which approximately equal to unity $\left(\mathrm{R}^{2}\right)$ but for 1000 return period differs which is still acceptable without any uncertainty for further application. So, the developed Rainfall intensity duration curves and derived empirical equations can be used for the planning and design of any Water Resources projects and infrastructure in the towns related to water resources.
\end{abstract}

Keywords: Rainfall IDF Curves, Western Part of Ethiopia, Gumbel Probability Distribution, Empirical Equation

\section{Introduction}

Rainfall is an important component in the hydrologic cycle. Quantification of rainfall is needed for planning and designing of various water resource projects as well as urban infrastructures. Quantification of rainfall is generally done using isopluvial maps and intensity-duration-frequency (IDF) curves [4].

The rainfall characteristics are often required to design water structures, reviewing and updating rainfall characteristics (i.e. Intensity-Duration -Frequency (IDF)) curves for future climate scenarios therefore, it becomes very necessary. The evaluation of rainfall is a major issue in hydrologic risk analysis and design [1].

The IDF relationship is the estimation of rainfall intensities of different rainfall durations and return periods [6]. The intensity-duration-frequency (IDF) relationship is one of the prerequisite statistics in water recourses engineering planning, development, and management and to assess the vulnerability of hydraulic structures. IDF curves describe the amount of rainfall in a watershed area for a given period of time [3].

An intensity-duration-frequency curve (IDF curve) is a mathematical function that relates the rainfall intensity with its duration and frequency of occurrence [3]. These curves are commonly used in hydrology for flood forecasting and civil engineering for urban drainage design. However, the $I D F$ curves are also analysed in hydrometeorology because of the interest in the time concentration or time-structure of the rainfall $[9,12]$.

Currently the country Ethiopia is under the rapid development of urbanization. The urbanization by its nature comprises the construction of building, Infrastructures, Water Supply structures construction and Electric line distribution. Some of the structure goes with urbanization needs the perfect estimation of design flood especially bridge, Culvert, Storm canal and ditches. So, to have accurately predicted 
Design Flood for different return period the development of Rainfall Intensity Duration Curve plays key role.

The Rainfall Intensity Duration Curve was not yet developed for the specified towns. Thus, the development of Rainfall Intensity Duration Curve will help the designer to estimate accurate design flood for the Hydraulic structures needed in the towns without causing low capacity and excess cost.

The objectives of this study are: to disaggregate daily Rainfall data to a common duration for design (5min, 10min, $15 \mathrm{~min}, 30 \mathrm{~min}, 1 \mathrm{hr}$, $3 \mathrm{hrs}$, 6hrs, $12 \mathrm{hrs}$ and $24 \mathrm{hrs}$ ), to develop Rainfall intensity duration curve for commonly adopted return period of time and to develop/Derive Empirical equation for Rainfall Intensity at different time and return period.

In Water Resources project management and monitoring, Rainfall Intensity-duration-frequency (IDF) curves are used for the design of infrastructures. At any specific gauged location, the rainfall intensity can be obtained for a given duration and frequency of occurrence (known as return period).

Therefore, the development of the Rainfall IDF curve and Empirical formula for Rainfall intensity versus time duration will help water resources project/ Infrastructure designer and decisions maker to predict the perfect design flood. The prediction of perfect design flood will help us to design the most Economical and efficient infrastructure components in the selected towns in western part of the country, Ethiopia.

\section{Description of Study Area}

Most of the town in which we tried to develop Rainfall Intensity duration curve are found in Oromia except Assossa and Gambella town which were found in Benishangul Gumuz Regional state and Gambella Regional state respectively [2]. All towns are under rapid growth (urbanization) so that infrastructures are under the construction which needs accurate prediction of design flood.

Table 1. Location of study area.

\begin{tabular}{llll}
\hline ID & Station Name & X-Coordinate & Y-Coordinate \\
\hline 1 & Assossa & 8644.14 & 1116515.91 \\
2 & Baco & 283470.41 & 1003178.18 \\
3 & Bedele & 191530.18 & 915231.77 \\
4 & DembiDollo & 40205.70 & 945445.38 \\
5 & Nedjo & 116556.45 & 1054097.92 \\
6 & Nekemte & 229599.28 & 1005719.86 \\
7 & Shambu & 293792.57 & 1058562.44 \\
8 & Gimbi & 805900.00 & 1014463.00 \\
9 & Metu & 784194.00 & 918387.00 \\
10 & Gambella & 5817483.47 & 1254777.63 \\
\hline
\end{tabular}

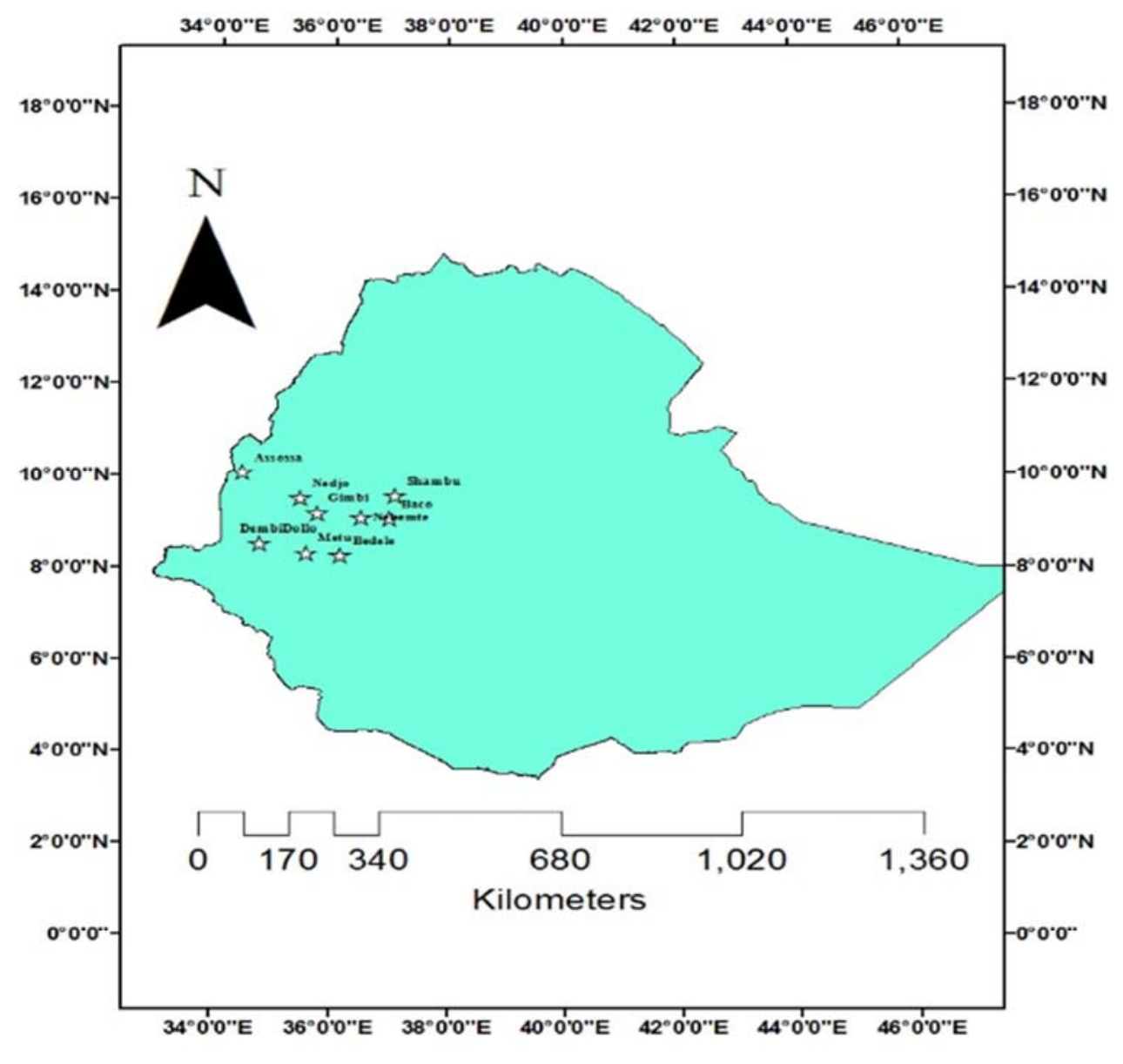

Figure 1. Location of study area. 


\section{Methodology and Materials}

The methodology used in this study was includes the following produces (1) Rainfall data collection; (2) Disaggregation of daily Rainfall data to commonly used hourly data. (3) Determining the annual maximum rainfall intensity for specific durations, (4) Frequency analysis by using empirical plotting position approach or theoretical Extreme Value (EV) distribution and (5) Plotting or Formulating duration versus Rainfall intensity curve/equation for further application of the research result.

\section{Rainfall Data collection:}

These data include primary and secondary data of the station we have been selected for the specified towns in western part of the country, Ethiopia.

Primary Data: These data includes physical characteristics of the station, which was collected by field observation and necessary measurement at the site using different instrument according to their importance and financial limitation.

Secondary Data: These data was obtained from Ministry of Water Resources, National Meteorological agency, Ethiopian mapping agency and etc, according to their importance for this particular study.

Table 2. Data used and their sources.

\begin{tabular}{lll}
\hline Data Types & Source & Availability Condition \\
\hline Meteorological Data & Metrological agency & Purchasing \\
Topographical Map & Ethiopian mapping agency & Purchasing by Km $^{2}$ \\
DEM data. & Ministry of Water Resources & Free \\
Physical data of station & Station & Site Observations \\
\hline
\end{tabular}

2. Disaggregation of daily Rainfall data to commonly used hourly data.

The problem of multiple site rainfall disaggregation presents significant differences from that of single-site disaggregation, including increased mathematical complexity. However, a multivariate approach to rainfall disaggregation is significant practical interest even in problems that are traditionally regarded as univariate. A univariate disaggregation model like Hyetos would generate a synthetic hourly series, fully consistent with the known daily series and, simultaneously, statistically consistent with the actual hourly rainfall series. Obviously, however, a synthetic series obtained by such a manner could not coincide with the actual one, but would be only a likely realization [7, 8]. Unfortunately, there is no station having hourly rainfall in the study area so that the equation proposed by Sai Htun Thein was used for rainfall disaggregation.

Generally, the overall procedure that was adopted in this study is as given in figure 3 .

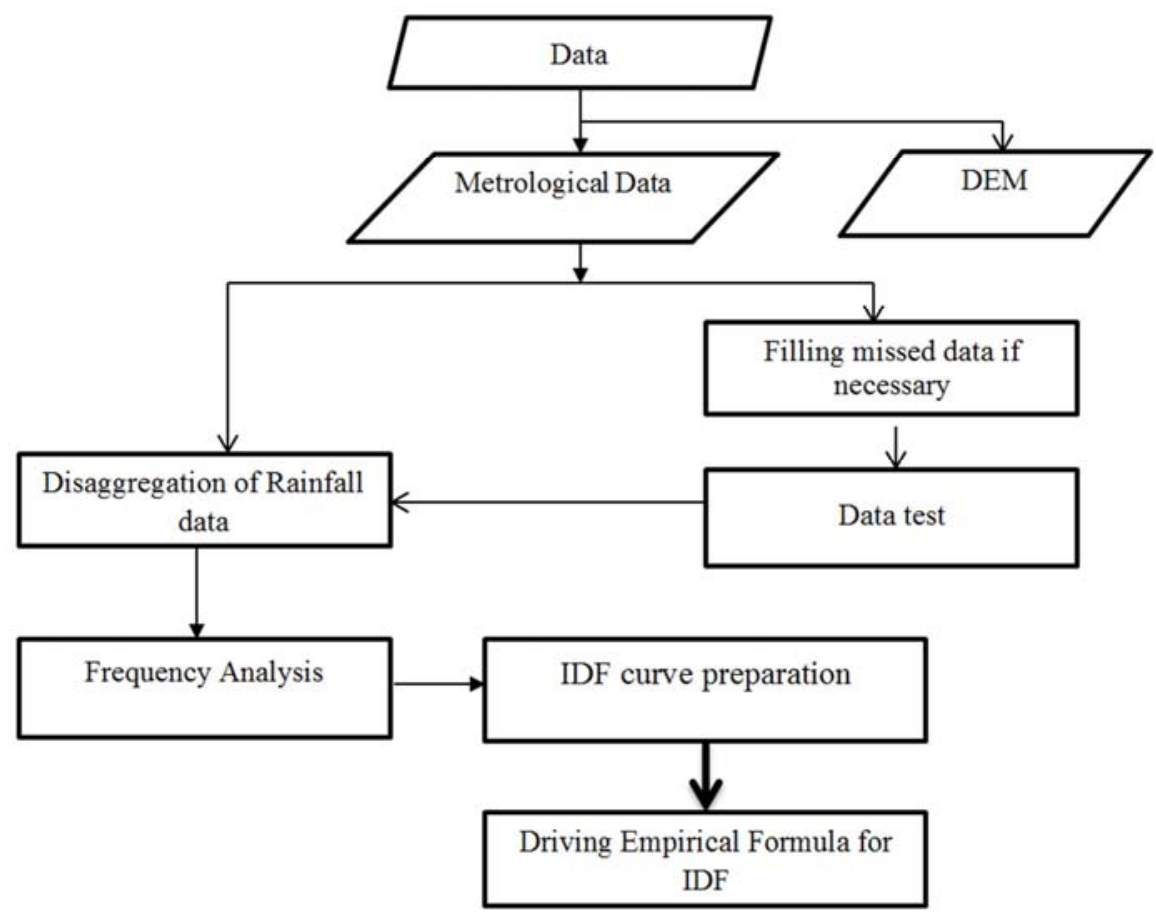

Figure 2. Methodology used for the study.

3. Disaggregation of daily Rainfall data to commonly used hourly data.

The problem of multiple site rainfall disaggregation presents significant differences from that of single-site disaggregation, including increased mathematical complexity. However, a multivariate approach to rainfall disaggregation 
is significant practical interest even in problems that are traditionally regarded as univariate. A univariate disaggregation model like Hyetos would generate a synthetic hourly series, fully consistent with the known daily series and, simultaneously, statistically consistent with the actual hourly rainfall series. Obviously, however, a synthetic series obtained by such a manner could not coincide with the actual one, but would be only a likely realization [8]. Unfortunately, there is no station having hourly rainfall in the study area so that the equation proposed by Sai Htun Thein was used for rainfall disaggregation [13].

\section{Frequency analysis}

The development of IDF curves requires that a frequency analysis be performed for each set of annual maxima, one each associated with each rainfall durations.

The basic objective of each frequency analysis is to determine the exceedance probability distribution function of rainfall intensity for each duration. Generally, there are two options for frequency analysis.

a) By Using an empirical plotting position approach to estimate the exceedance probabilities based on the observations. The procedures are:

i. Rank the observations in descending order.

ii. Compute the exceedance probability associated with each rainfall volume using the following expression,

$$
P=\frac{1}{T}=\frac{r a n k}{m+1}
$$

Where $\mathrm{m}$ is the number of observations,

$\mathrm{P}$ is the exceedance probability and.

$\mathrm{T}$ is the corresponding return period.

iii. Transform the volume data into rainfall intensity by dividing volume by the corresponding duration,

iv. Plot empirical distribution of rainfall intensity versus commonly selected duration.

b) Fit a theoretical Extreme Value (EV) distribution (e.g., Gumbel Type I) to the observations and then use the theoretical distribution to estimate the rainfall events associated with given exceedance probabilities. There are a number of probability distribution functions that can be used to describe extreme value data such as annual maxima. These include log-normal (two Parameters), Normal, Type I Extreme value (Gumbel), Type III Extreme value, Log-Pearson Type III, and Gamma distribution. The probability distribution function which will be fitted to each selected duration data series to obtain the design rainfall depth for $5 \mathrm{~min}$, $10 \mathrm{~min}, 15 \mathrm{~min}, 30 \mathrm{~min}, 1 \mathrm{hr}, 3 \mathrm{hrs}$, $6 \mathrm{hrs}$, $12 \mathrm{hrs}$ and $24 \mathrm{hrs}$ return period was selected as best fitted function [10]. The Kolmogorov-Smirnov and chi-square goodness of fit test will be used to evaluate the accuracy of the fittings of distribution.

\section{Gumbel theory of distribution}

Gumbel distribution methodology was selected to perform the flood probability analysis. The Gumbel theory of distribution is the most widely used distribution for IDF analysis owing to its suitability for modelling maxima. It is relatively simple and uses only extreme events (maximum values or peak rainfalls). The Gumbel method calculates the 2 , $5,10,25,50,100$ and 1000 years return intervals for each duration period and requires several calculations. Frequency precipitation PT (in $\mathrm{mm}$ ) for each duration with a specified return period $\mathrm{T}$ (in year) is given by the following equation [5].

$$
P_{T}=P_{a v}+K S
$$

Where:

$\mathrm{K}$ is the Gumbel Frequency factor given by:

$$
K=-\frac{\sqrt{6}}{\pi}\left[0.5772+\ln \left[\ln \left[\frac{T}{T-1}\right]\right]\right] .
$$

$\mathrm{P}_{\mathrm{av}}$ is the average of maximum precipitation corresponding to a specific duration which is given by:

$$
P_{a v}=\frac{1}{n} \sum_{i=1}^{n} P_{i}
$$

Where $\mathrm{Pi}$ is the individual extreme value of rainfall and $\mathrm{n}$ is the number of events or years of record.

$\mathrm{S}$ is the standard deviation determined by:

$$
S=\left[\frac{1}{n-1} \sum_{i=1}^{n}\left(P_{i}-P_{a v}\right)^{2}\right]^{1 / 2}
$$

5. Plotting or Formulating duration versus Rainfall intensity curve/equation

The step taken to develop intensity-duration-frequency curve is as follows [1].

a. Preparation of annual maximum data series (Disaggregation)

The annual maximum rainfall depths for the different durations (5min, 10min, 15min, 30min, $1 \mathrm{hr}$, 2hrs, 6hrs, $12 \mathrm{hrs}$ and $24 \mathrm{hrs}$ ) was calculated by using the equation proposed by $[11,13]$.

$$
P_{t}=P_{24}\left(\frac{t}{24}\right)^{1 / 3}
$$

Where,

$\mathrm{P}_{\mathrm{t}}=$ the required precipitation depth in $\mathrm{mm}$ for the duration of t-hour

$\mathrm{P}_{24}=$ annual maximum daily rainfall $(\mathrm{mm})$ and

$\mathrm{t}=$ the time duration (in hours) for the required precipitation depth.

\section{b. Rainfall intensity determination}

Rainfall intensity is the rate of precipitation, depth of precipitation per unit time. The average intensity is commonly used.

$$
I=\frac{P}{t_{d}}
$$

Where; $\mathrm{P}$ is the rainfall depth,

$t_{d}$ is the duration of rainfall.

The intensities were computed for each year and then ranked in descending order with the highest value taking the value of 1 in the rank. The intensity values data subjected to statistical analysis to determine the mean $(\bar{X})$ and standard 
deviation (S).

c. Fittings the probability distribution

Among the probability distribution functions, Gumbel theory of distribution for each duration data series to obtain the design rainfall depth for commonly used time duration and return period was selected based on the skew values.

\section{d. Determination the rainfall depth}

The frequency factors or the CDF of the distribution (by inverting the CDF) are the two commonly available methods that can be used to determine rainfall depth. The frequency factor was used for the data and the rainfall depth calculations depend on the probability distribution function selected for considered return period.

The IDF curves were then developed by plotting the design rainfall intensity values against corresponding durations for the different return period.

e. Derivation of IDF empirical formula

Derivation of IDF empirical formula a power function can describe generalized IDF relationship between rainfall intensity $(\mathrm{I})$, rainfall duration $(\mathrm{t})$ and return period $(\mathrm{T})$ [6]. The following procedure was used to derive a formula for intensity of rainfall I from the IDF relationships:

The general form of intensity equation can be defined in the form of power-law relation as in equation.

$$
I=\frac{C T^{m}}{t^{a}}
$$

Where I is the intensity of rainfall ( $\mathrm{mm} / \mathrm{hr}$.),

$t$ is the duration of rainfall (minutes),

$\mathrm{T}$ is the returning period (years) and

Constants $(\mathrm{C}, \mathrm{m}$ and $\mathrm{a})$ are empirical parameters depend on precipitation data, shape, size and location of the study area which can obtained from logarithmic transformation of the equation.

\section{Results and Discussions}

The main purpose of the study was to develop Rainfall intensity Duration curves and to derive an empirical formula to estimate the rainfall intensity at the considered towns in western part of the country, Ethiopia.
The IDF curves are used as an aid when designing drainage structures for any engineering project. The curves allow the engineer to design safe and economical flood control measures, cross drainage structure, urban infrastructure and etc. in the towns. Rainfall estimates in $\mathrm{mm}$ and their intensities in $\mathrm{mm} / \mathrm{hr}$. for various return periods and different time durations were analyzed using Gumbel's Extreme Value Distribution Function along with Log person type III techniques (Tables 3-12) then the empirical formula derived using logarithmic transformation approach using the rainfall intensity estimated by Gumbel's Extreme Value Distribution Function (Table 14).

The IDF curves developed by Gumbel's Extreme value distribution shows, the pattern similarity for all return period, duration and all considered stations but the rainfall intensity shows an increasing with increase in the return period and decrease with rainfall duration increase in all return periods. The empirical equation derived using logarithmic transformation approach has also shows good estimation of objective function (summation of error square) and parameter estimation $(\mathrm{C}, \mathrm{m}, \mathrm{a})$ for return period of $2,5,10,25,50,100$ years but tolerable result for return period of 1000 years (Figure 4).

The rainfall intensity duration Curves shows high rainfall intensity variation for small time duration for different return period (For 1hour time duration the difference of rainfall intensity from 2 to 1000 return period is about $200 \mathrm{~mm} / \mathrm{hr}$ to $300 \mathrm{~mm} / \mathrm{hr}$ from station to station) but as time duration becomes larger and larger the rainfall intensity variation reduced almost negligible for all return period considered for this particular study (after 9hour time duration almost for station the curves becomes closer to each other which is the indication negligible differences).

The comparison was also made between rainfall developed by using Gamble's Probability distribution and computed by Derived Empirical equation. In all return period and duration of time it shows good relation which approximately equal to unity $\left(\mathrm{R}^{2}\right)$ for all towns but for 1000 return period little bit different from the other return period which is still acceptable without any uncertainty for further application (Table 13).

Table 3. Shambu Computed Rainfall intensity ( $\mathrm{mm} / \mathrm{hr}$.) at different return Period and Duration by Gumbel's Methods.

\begin{tabular}{|c|c|c|c|c|c|c|c|}
\hline \multirow{2}{*}{ Duration (min) } & \multicolumn{7}{|c|}{ Shambu Rainfall intensity (mm/hr.) at different return Period and Duration by Gumbel's } \\
\hline & 2-years & 5-years & 10-years & 25-years & 50-years & 100-years & 1000-years \\
\hline 5 & 93.56 & 136.87 & 136.87 & 158.67 & 174.84 & 190.89 & 19.51 \\
\hline 10 & 55.47 & 81.15 & 81.15 & 94.08 & 103.67 & 113.18 & 24.59 \\
\hline 15 & 43.18 & 63.17 & 63.17 & 73.23 & 80.69 & 88.10 & 28.15 \\
\hline 30 & 27.20 & 39.79 & 39.79 & 46.13 & 50.83 & 55.50 & 35.46 \\
\hline 60 & 17.14 & 25.07 & 25.07 & 29.06 & 32.02 & 34.96 & 44.68 \\
\hline 180 & 7.20 & 10.53 & 10.53 & 12.21 & 13.45 & 14.68 & 56.29 \\
\hline 360 & 5.19 & 7.59 & 7.59 & 8.80 & 9.70 & 10.59 & 81.19 \\
\hline 720 & 3.27 & 4.78 & 4.78 & 5.54 & 6.11 & 6.67 & 102.29 \\
\hline 1080 & 2.50 & 3.65 & 3.65 & 4.23 & 4.66 & 5.09 & 117.09 \\
\hline 1440 & 2.06 & 3.01 & 3.01 & 3.49 & 3.85 & 4.20 & 128.87 \\
\hline
\end{tabular}


Table 4. Nekemte Computed Rainfall Intensity ( $\mathrm{mm} / \mathrm{hr}$.) at different return Period and Duration by Gumbel's Methods.

\begin{tabular}{|c|c|c|c|c|c|c|c|}
\hline \multirow{2}{*}{ Duration (min) } & \multicolumn{7}{|c|}{ Nekemte Rainfall Intensity (mm/hr.) at different return Period and Duration by Gumbel } \\
\hline & 2-years & 5-years & 10-years & 25-years & 50-years & 100 -years & 1000-years \\
\hline 5 & 143.803 & 180.955 & 205.553 & 236.632 & 259.689 & 282.575 & 358.198 \\
\hline 10 & 85.262 & 107.289 & 121.873 & 140.300 & 153.970 & 167.540 & 212.377 \\
\hline 15 & 66.368 & 83.514 & 94.867 & 109.211 & 119.852 & 130.414 & 165.316 \\
\hline 30 & 41.809 & 52.611 & 59.762 & 68.798 & 75.502 & 82.156 & 104.142 \\
\hline 60 & 26.338 & 33.143 & 37.648 & 43.340 & 47.563 & 51.755 & 65.606 \\
\hline 180 & 11.061 & 13.919 & 15.811 & 18.202 & 19.975 & 21.736 & 27.553 \\
\hline 360 & 7.977 & 10.037 & 11.402 & 13.126 & 14.405 & 15.674 & 19.869 \\
\hline 720 & 5.025 & 6.323 & 7.183 & 8.269 & 9.074 & 9.874 & 12.517 \\
\hline 1080 & 3.835 & 4.825 & 5.481 & 6.310 & 6.925 & 7.535 & 9.552 \\
\hline 1440 & 3.166 & 3.983 & 4.525 & 5.209 & 5.716 & 6.220 & 7.885 \\
\hline
\end{tabular}

Table 5. Gimbi Computed Rainfall Intensity ( $\mathrm{mm} / \mathrm{hr}$.) at different return Period and Duration by Gumbel's Methods.

\begin{tabular}{|c|c|c|c|c|c|c|c|}
\hline \multirow{2}{*}{ Duration (min) } & \multicolumn{7}{|c|}{ Gimbi Rainfall Intensity (mm/hr.) at different return Period and Duration by Gumbel } \\
\hline & 2-years & 5-years & 10-years & 25-years & 50-years & 100-years & 1000-years \\
\hline 5 & 108.846 & 141.876 & 163.745 & 191.377 & 211.875 & 232.222 & 299.455 \\
\hline 10 & 64.535 & 84.119 & 97.085 & 113.468 & 125.622 & 137.685 & 177.548 \\
\hline 15 & 50.235 & 65.479 & 75.572 & 88.324 & 97.785 & 107.175 & 138.205 \\
\hline 30 & 31.646 & 41.249 & 47.607 & 55.641 & 61.600 & 67.516 & 87.063 \\
\hline 60 & 19.936 & 25.985 & 29.991 & 35.051 & 38.806 & 42.532 & 54.847 \\
\hline 180 & 8.372 & 10.913 & 12.595 & 14.721 & 16.297 & 17.863 & 23.034 \\
\hline 360 & 6.038 & 7.870 & 9.083 & 10.615 & 11.752 & 12.881 & 16.610 \\
\hline 720 & 3.803 & 4.958 & 5.722 & 6.687 & 7.404 & 8.115 & 10.464 \\
\hline 1080 & 2.903 & 3.783 & 4.367 & 5.103 & 5.650 & 6.193 & 7.985 \\
\hline 1440 & 2.396 & 3.123 & 3.604 & 4.213 & 4.664 & 5.112 & 6.592 \\
\hline
\end{tabular}

Table 6. Bedele Computed Rainfall Intensity ( $\mathrm{mm} / \mathrm{hr}$.) at different return Period and Duration by Gumbel's Methods.

\begin{tabular}{|c|c|c|c|c|c|c|c|}
\hline \multirow{2}{*}{ Duration (min) } & \multicolumn{7}{|c|}{ Bedele Rainfall Intensity (mm/hr.) at different return Period and Duration by Gumbel } \\
\hline & 2-years & 5-years & 10-years & 25-years & 50-years & 100-years & 1000-years \\
\hline 5 & 109.316 & 133.482 & 149.482 & 169.697 & 184.694 & 199.581 & 248.770 \\
\hline 10 & 64.814 & 79.142 & 88.628 & 100.614 & 109.506 & 118.332 & 147.497 \\
\hline 15 & 50.452 & 61.605 & 68.989 & 78.319 & 85.240 & 92.111 & 114.812 \\
\hline 30 & 31.783 & 38.808 & 43.460 & 49.338 & 53.698 & 58.026 & 72.327 \\
\hline 60 & 20.022 & 24.448 & 27.378 & 31.081 & 33.828 & 36.554 & 45.563 \\
\hline 180 & 8.409 & 10.267 & 11.498 & 13.053 & 14.207 & 15.352 & 19.135 \\
\hline 360 & 6.064 & 7.404 & 8.292 & 9.413 & 10.245 & 11.071 & 13.799 \\
\hline 720 & 3.820 & 4.664 & 5.223 & 5.930 & 6.454 & 6.974 & 8.693 \\
\hline 1080 & 2.915 & 3.560 & 3.986 & 4.525 & 4.925 & 5.322 & 6.634 \\
\hline 1440 & 2.406 & 2.938 & 3.291 & 3.736 & 4.066 & 4.393 & 5.476 \\
\hline
\end{tabular}

Table 7. Assosa Computed Rainfall Intensity (mm/hr.) at different return Period and Duration by Gumbel's Methods.

\begin{tabular}{|c|c|c|c|c|c|c|c|}
\hline \multirow{2}{*}{ Duration (min) } & \multicolumn{7}{|c|}{ Assosa Rainfall Intensity ( $\mathrm{mm} / \mathrm{hr}$.) at different return Period and Duration by Gumbel } \\
\hline & 2-years & 5-years & 10-years & 25-years & 50-years & 100-years & 1000-years \\
\hline 5 & 116.583 & 152.477 & 176.243 & 206.270 & 228.546 & 250.658 & 323.722 \\
\hline 10 & 69.122 & 90.404 & 104.495 & 122.298 & 135.506 & 148.616 & 191.936 \\
\hline 15 & 53.805 & 70.371 & 81.340 & 95.198 & 105.479 & 115.684 & 149.404 \\
\hline 30 & 33.895 & 44.331 & 51.241 & 59.971 & 66.447 & 72.876 & 94.119 \\
\hline 60 & 21.353 & 27.927 & 32.280 & 37.779 & 41.859 & 45.909 & 59.291 \\
\hline 180 & 8.968 & 11.729 & 13.557 & 15.866 & 17.580 & 19.281 & 24.901 \\
\hline 360 & 6.467 & 8.458 & 9.776 & 11.442 & 12.677 & 13.904 & 17.957 \\
\hline 720 & 4.074 & 5.328 & 6.158 & 7.208 & 7.986 & 8.759 & 11.312 \\
\hline 1080 & 3.109 & 4.066 & 4.700 & 5.501 & 6.095 & 6.684 & 8.633 \\
\hline 1440 & 2.566 & 3.356 & 3.880 & 4.541 & 5.031 & 5.518 & 7.126 \\
\hline
\end{tabular}


Table 8. Nedjo Computed Rainfall Intensity (mm/hr.) at different return Period and Duration by Gumbel's Methods.

\begin{tabular}{llllllll}
\hline \multirow{2}{*}{ Duration (min) } & \multicolumn{2}{l}{ Nedjo Rainfall Intensity $(\mathbf{m m} / \mathbf{h r}$.) at different return Period and Duration by Gumbel } \\
\cline { 2 - 7 } & 2-years & 5-years & 10-years & 25-years & 50-years & 100-years & 1000-years \\
\hline 5 & 107.295 & 132.598 & 149.351 & 170.519 & 186.222 & 201.809 & 253.314 \\
10 & 63.615 & 78.618 & 88.551 & 101.101 & 110.412 & 119.653 & 150.191 \\
15 & 49.519 & 61.197 & 68.928 & 78.698 & 85.945 & 93.139 & 116.910 \\
30 & 31.195 & 38.551 & 43.422 & 49.576 & 54.142 & 58.674 & 73.648 \\
60 & 19.651 & 24.286 & 27.354 & 31.231 & 34.107 & 36.962 & 46.396 \\
180 & 8.253 & 10.199 & 11.488 & 13.116 & 14.324 & 15.523 & 19.485 \\
360 & 5.952 & 7.355 & 8.284 & 9.458 & 10.330 & 11.194 & 14.051 \\
720 & 3.749 & 4.633 & 5.219 & 5.958 & 6.507 & 7.052 & 8.852 \\
1080 & 2.861 & 3.536 & 3.983 & 4.547 & 4.966 & 5.382 & 6.755 \\
1440 & 2.362 & 2.919 & 3.288 & 3.754 & 4.099 & 4.442 & 5.576 \\
\hline
\end{tabular}

Table 9. DembiDollo Computed Rainfall Intensity $(\mathrm{mm} / \mathrm{hr}$.) at different return Period and Duration by Gumbel's Methods.

\begin{tabular}{llllllll}
\hline \multirow{2}{*}{ Duration (min) } & \multicolumn{7}{l}{ DembiDollo Rainfall Intensity $(\mathbf{m m} / \mathbf{h r}$ ) at different return Period and Duration by Gumbel } \\
\cline { 2 - 8 } & 2-years & 5-years & 10-years & 25-years & 50-years & 100-years & 1000-years \\
\hline 5 & 85.166 & 99.178 & 108.455 & 120.177 & 128.873 & 137.505 & 166.027 \\
10 & 50.495 & 58.803 & 64.304 & 71.254 & 76.409 & 81.527 & 98.438 \\
15 & 39.306 & 45.773 & 50.054 & 55.464 & 59.477 & 63.461 & 76.625 \\
30 & 24.761 & 28.835 & 31.532 & 34.940 & 37.468 & 39.978 & 48.270 \\
60 & 15.599 & 18.165 & 19.864 & 22.011 & 23.604 & 25.185 & 30.408 \\
180 & 6.551 & 7.629 & 8.342 & 9.244 & 9.913 & 10.577 & 12.771 \\
360 & 4.724 & 5.501 & 6.016 & 6.666 & 7.148 & 7.627 & 9.209 \\
720 & 2.976 & 3.466 & 3.790 & 4.199 & 4.503 & 4.805 & 5.802 \\
1080 & 2.271 & 2.645 & 2.892 & 3.205 & 3.437 & 3.667 & 4.427 \\
1440 & 1.875 & 2.183 & 2.387 & 2.645 & 2.837 & 3.027 & 3.655 \\
\hline
\end{tabular}

Table 10. Mettu Computed Rainfall Intensity ( $\mathrm{mm} / \mathrm{hr}$.) at different return Period and Duration by Gumbel's Methods.

\begin{tabular}{llllllll}
\hline \multirow{2}{*}{ Duration ( $\mathbf{m i n})$} & \multicolumn{2}{l}{ Mettu Rainfall Intensity (mm/hr) at different return Period and Duration by Gumbel } \\
\cline { 2 - 7 } & 2-years & 5-years & 10-years & 25-years & 50-years & 100-years & 1000-years \\
\hline 5 & 100.973 & 122.769 & 137.200 & 155.434 & 168.961 & 182.388 & 226.755 \\
10 & 59.867 & 72.790 & 81.347 & 92.157 & 100.178 & 108.138 & 134.444 \\
15 & 46.601 & 56.660 & 63.321 & 71.736 & 77.979 & 84.176 & 104.652 \\
30 & 29.357 & 35.694 & 39.889 & 45.191 & 49.124 & 53.027 & 65.927 \\
60 & 18.494 & 22.486 & 25.129 & 28.468 & 30.946 & 33.405 & 41.531 \\
180 & 7.767 & 9.443 & 10.553 & 11.956 & 12.996 & 14.029 & 17.442 \\
360 & 5.601 & 6.810 & 7.610 & 8.622 & 9.372 & 10.117 & 12.578 \\
720 & 3.528 & 4.290 & 4.794 & 5.431 & 5.904 & 6.373 & 7.924 \\
1080 & 2.693 & 3.274 & 3.659 & 4.145 & 4.506 & 4.864 & 6.047 \\
1440 & 2.223 & 2.702 & 3.020 & 3.422 & 3.719 & 4.015 & 4.992 \\
\hline
\end{tabular}

Table 11. Bako Computed Rainfall Intensity ( $\mathrm{mm} / \mathrm{hr}$.) at different return Period and Duration by Gumbel's Methods.

\begin{tabular}{llllllll}
\hline \multirow{2}{*}{ Duration (min) } & \multicolumn{2}{l}{ Bako Rainfall Intensity (mm/hr.) at different return Period and Duration by Gumbel } \\
\cline { 2 - 7 } & 2-years & 5-years & 10-years & 25-years & 50-years & 100-years & 1000-years \\
\hline 5 & 84.106 & 108.346 & 124.396 & 144.675 & 159.718 & 174.651 & 223.994 \\
10 & 49.867 & 64.239 & 73.755 & 85.778 & 94.698 & 103.551 & 132.807 \\
15 & 38.816 & 50.004 & 57.411 & 66.770 & 73.713 & 80.605 & 103.378 \\
30 & 24.453 & 31.501 & 36.167 & 42.063 & 46.436 & 50.778 & 65.124 \\
60 & 15.404 & 19.844 & 22.784 & 26.498 & 29.253 & 31.988 & 41.025 \\
180 & 6.469 & 8.334 & 9.569 & 11.128 & 12.286 & 13.434 & 17.230 \\
360 & 4.665 & 6.010 & 6.900 & 8.025 & 8.859 & 9.688 & 12.425 \\
720 & 2.939 & 3.786 & 4.347 & 5.055 & 5.581 & 6.103 & 7.827 \\
1080 & 2.243 & 2.889 & 3.317 & 3.858 & 4.259 & 4.657 & 5.973 \\
1440 & 1.851 & 2.385 & 2.738 & 3.185 & 3.516 & 3.845 & 4.931 \\
\hline
\end{tabular}


Table 12. Gambella Computed Rainfall Intensity ( $\mathrm{mm} / \mathrm{hr}$ ) at different return Period and Duration by Gumbel's Methods.

\begin{tabular}{llllllll}
\hline \multirow{2}{*}{ Duration (min) } & \multicolumn{6}{l}{ Gambella Rainfall Intensity $(\mathbf{m m} / \mathbf{h r}$ ) at different return Period and Duration by Gumbel } \\
\cline { 2 - 7 } & 2-years & 5-years & 10-years & 25-years & 50-years & 100-years & 1000-years \\
\hline 5 & 136.089 & 170.647 & 193.527 & 222.436 & 243.882 & 265.170 & 335.512 \\
10 & 80.688 & 101.177 & 114.743 & 131.883 & 144.599 & 157.220 & 198.927 \\
15 & 62.808 & 78.757 & 89.317 & 102.659 & 112.556 & 122.381 & 154.846 \\
30 & 39.567 & 49.614 & 56.266 & 64.671 & 70.906 & 77.095 & 97.547 \\
60 & 24.925 & 31.255 & 35.445 & 40.740 & 44.668 & 48.567 & 61.451 \\
180 & 10.468 & 13.126 & 14.886 & 17.110 & 18.759 & 20.397 & 25.808 \\
360 & 7.549 & 9.466 & 10.735 & 12.338 & 13.528 & 14.709 & 18.611 \\
720 & 4.755 & 5.963 & 6.762 & 7.773 & 8.522 & 9.266 & 11.724 \\
1080 & 3.629 & 4.551 & 5.161 & 5.932 & 6.504 & 7.071 & 8.947 \\
1440 & 2.996 & 3.756 & 4.260 & 4.896 & 5.369 & 5.837 & 7.386 \\
\hline
\end{tabular}
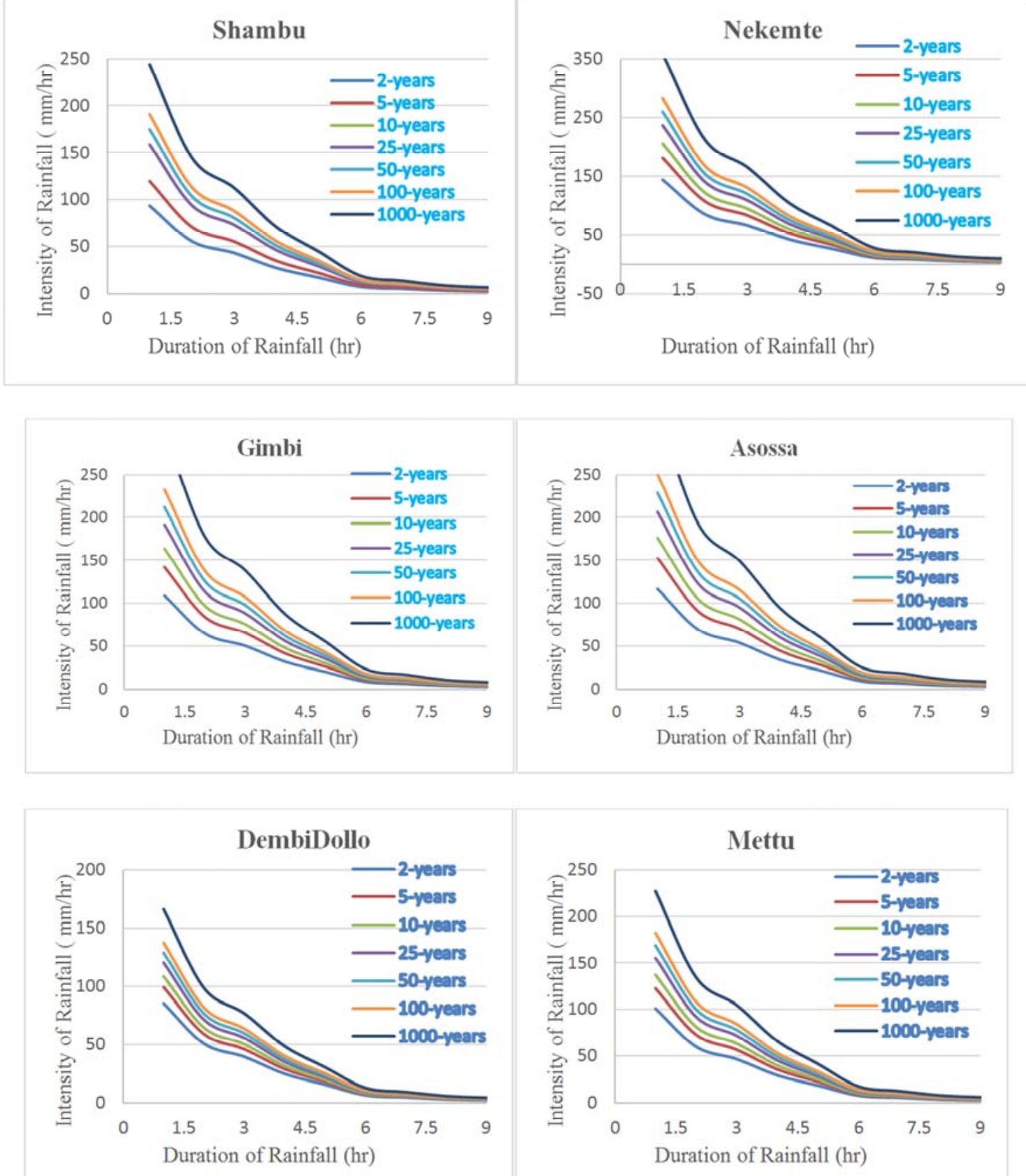

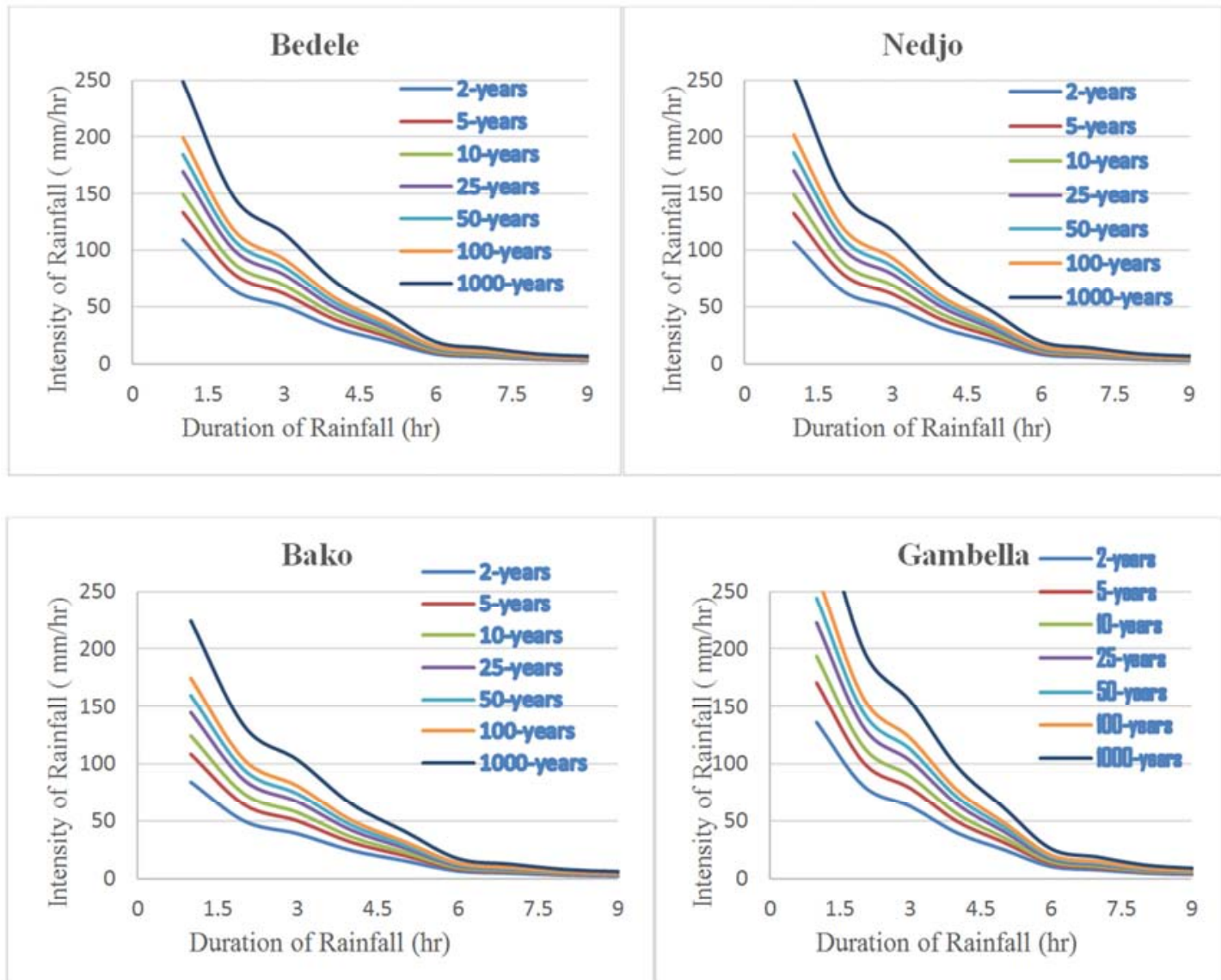

Figure 3. Developed Rainfall intensity Duration Curves by Gumbel's probability distribution function.

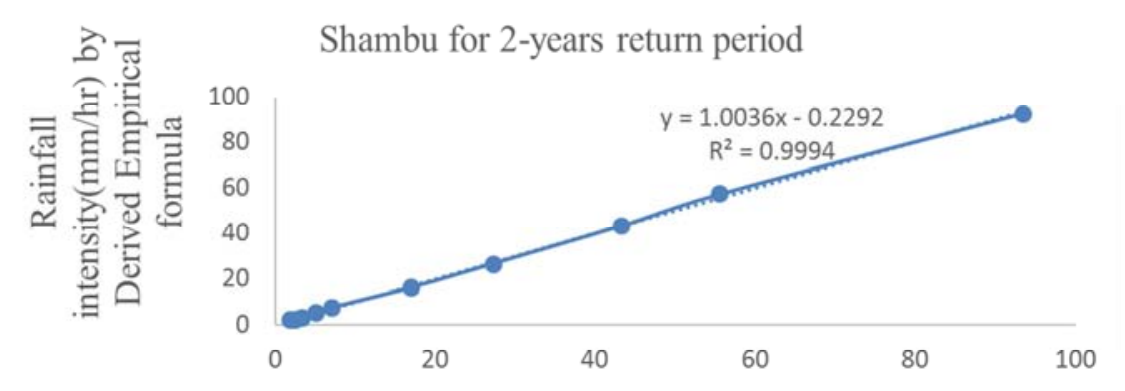

Rainfall Intensity(mm/hr) by Gumbel's

Figure 4. Correlation between Rainfall Intensity by Gumbel's and Derived Empirical formula.

Table 13. Correlation Coefficient $\left(R^{2}\right)$ Derived Empirical Equations and by Gumbel's Method.

\begin{tabular}{llllllll}
\hline \multirow{2}{*}{ Station/town } & \multicolumn{7}{c}{$\mathbf{R}^{2}$ Values between Rainfall Intensity developed by Gumbel's and Derived Empirical Equation at different return period } \\
\cline { 2 - 7 } & $\mathbf{2}$ & $\mathbf{5}$ & $\mathbf{1 0}$ & $\mathbf{2 5}$ & $\mathbf{5 0}$ & $\mathbf{1 0 0}$ & $\mathbf{1 0 0 0}$ \\
\hline Shambu & 0.9994 & 0.9994 & 0.9994 & 0.9994 & 0.9994 & 0.9994 & 0.4855 \\
Bako & 0.9994 & 0.9994 & 0.9994 & 0.9994 & 0.9994 & 0.9994 & 0.9834 \\
Nekemte & 0.9994 & 0.9994 & 0.9994 & 0.9994 & 0.9994 & 0.9994 & 0.9849 \\
Gimbi & 0.9999 & 0.9999 & 0.9999 & 0.9999 & 0.9999 & 0.9999 & 0.9806 \\
Bedele & 0.9999 & 0.9999 & 0.9999 & 0.9999 & 0.9999 & 0.9999 & 0.9851 \\
Mettu & 0.9999 & 0.9999 & 0.9999 & 0.9999 & 0.9999 & 0.9999 & 0.9856 \\
Nedjo & 0.9999 & 0.9999 & 0.9999 & 0.9999 & 0.9999 & 0.9999 & 0.9842 \\
DembiDollo & 0.9999 & 0.9999 & 0.9999 & 0.9999 & 0.9999 & 0.9999 & 0.9889 \\
Asossa & 0.9999 & 0.9999 & 0.9999 & 0.9999 & 0.9999 & 0.9999 & 0.9804 \\
Gambella & 0.9994 & 0.9994 & 0.9994 & 0.9994 & 0.9994 & 0.9994 & 0.9851 \\
\hline
\end{tabular}


Table 14. Values of Constant $C, m$ and a for derived Empirical formula.

\begin{tabular}{|c|c|c|c|c|c|c|c|c|c|c|c|c|c|c|c|}
\hline \multirow{2}{*}{$\begin{array}{l}\text { Return } \\
\text { period }\end{array}$} & \multicolumn{3}{|c|}{ Shambu } & \multicolumn{3}{|c|}{ Nekemte } & \multicolumn{3}{|l|}{ Gimbi } & \multicolumn{3}{|c|}{ Bedele } & \multicolumn{3}{|c|}{ Assosa } \\
\hline & $\mathrm{C}$ & $\mathbf{m}$ & $\mathbf{a}$ & $\mathrm{C}$ & $\mathbf{m}$ & $\mathbf{a}$ & C & $\mathbf{m}$ & $\mathbf{a}$ & C & $\mathbf{m}$ & $\mathbf{a}$ & $\mathrm{C}$ & $\mathbf{m}$ & $\mathbf{a}$ \\
\hline 2 & 5.250 & 5.763 & 0.697 & 5.351 & 6.356 & 0.697 & 5.227 & 5.915 & 0.679 & 9.726 & 5.025 & 0.679 & 2.476 & 7.092 & 0.679 \\
\hline 5 & 5.237 & 2.636 & 0.697 & 5.327 & 2.883 & 0.697 & 5.232 & 2.711 & 0.679 & 5.254 & 2.671 & 0.679 & 5.266 & 2.752 & 0.679 \\
\hline 10 & 4.347 & 1.982 & 0.697 & 4.419 & 2.152 & 0.697 & 4.417 & 2.031 & 0.679 & 4.436 & 1.990 & 0.679 & 4.439 & 2.061 & 0.679 \\
\hline 25 & 4.858 & 1.429 & 0.697 & 4.939 & 1.548 & 0.697 & 4.873 & 1.471 & 0.679 & 4.883 & 1.433 & 0.679 & 4.886 & 1.493 & 0.679 \\
\hline 50 & 1.972 & 1.431 & 0.697 & 1.984 & 1.531 & 0.697 & 1.976 & 1.467 & 0.679 & 1.981 & 1.431 & 0.679 & 1.983 & 1.485 & 0.679 \\
\hline 100 & 1.089 & 1.364 & 0.697 & 1.095 & 1.448 & 0.697 & 1.088 & 1.396 & 0.679 & 1.090 & 1.362 & 0.679 & 1.091 & 1.412 & 0.679 \\
\hline 1000 & 0.974 & 1.227 & 3.405 & 2.100 & 1.154 & 1.762 & 1.008 & 1.049 & 0.988 & 1.008 & 1.023 & 0.993 & 1.005 & 1.060 & 0.986 \\
\hline \multirow{2}{*}{$\begin{array}{l}\text { Return } \\
\text { period }\end{array}$} & \multicolumn{3}{|l|}{ Nedjo } & \multicolumn{3}{|c|}{ Dembidollo } & \multicolumn{3}{|l|}{ Mettu } & \multicolumn{3}{|l|}{ Bako } & \multicolumn{3}{|c|}{ Gambella } \\
\hline & $\mathrm{C}$ & $\mathbf{m}$ & $\mathbf{a}$ & C & $\mathbf{m}$ & $\mathbf{a}$ & C & $\mathbf{m}$ & $\mathbf{a}$ & $\mathrm{C}$ & $\mathbf{m}$ & $\mathbf{a}$ & $\mathrm{C}$ & $\mathbf{m}$ & $\mathbf{a}$ \\
\hline 2 & 2.543 & 6.933 & 0.679 & 5.166 & 5.578 & 0.679 & 6.192 & 5.562 & 0.679 & 6.216 & 5.365 & 0.697 & 6.292 & 6.042 & 0.697 \\
\hline 5 & 5.312 & 2.660 & 0.679 & 5.219 & 2.490 & 0.679 & 5.278 & 2.616 & 0.679 & 5.284 & 2.569 & 0.697 & 5.361 & 2.842 & 0.697 \\
\hline 10 & 4.436 & 1.989 & 0.679 & 4.404 & 1.853 & 0.679 & 4.455 & 1.950 & 0.679 & 4.466 & 1.929 & 0.697 & 4.519 & 2.116 & 0.697 \\
\hline 25 & 4.883 & 1.433 & 0.679 & 0.990 & 1.821 & 0.679 & 4.905 & 1.404 & 0.679 & 4.916 & 1.397 & 0.697 & 4.982 & 1.526 & 0.697 \\
\hline 50 & 2.042 & 1.425 & 0.679 & 0.928 & 1.533 & 0.679 & 1.990 & 1.407 & 0.679 & 2.000 & 1.404 & 0.697 & 2.007 & 1.512 & 0.697 \\
\hline 100 & 1.860 & 1.249 & 0.679 & 1.074 & 1.285 & 0.679 & 1.095 & 1.342 & 0.679 & 1.104 & 1.342 & 0.697 & 1.101 & 1.433 & 0.697 \\
\hline 1000 & 1.009 & 1.025 & 0.991 & 1.001 & 1.481 & 3.265 & 2.001 & 2.210 & 6.716 & 2.001 & 2.224 & 6.615 & 0.985 & 1.593 & 3.213 \\
\hline
\end{tabular}

\section{Conclusions}

Rainfall Intensity duration Curve is very important for the towns are under a rapid urbanization so that for this particular study, Gamble's Extreme Value distribution method is the most preferable approach for IDF development of the considered part of the country. The rainfall intensity curves for small time duration shows high variation but as time the duration becomes larger and larger the intensity variation reduced almost negligible for all return period considered for this particular study. For return period of 1000year the Gumbel's probability distribution function does not show good relation in empirical derivation of rainfall intensity duration curve.

\section{Conflict of Interest}

The authors declare that they have no competing interests.

\section{References}

[1] Awofadeju A. S., A. A. (2018). Development of Rainfall Intensity-Duration-Frequency. International Journal of Engineering and Technology, Vol. 10, No. 4, August 2018.

[2] Awulachew, A. D. (2009). Characterization and Atlas of the Blue Nile Basin. International Water Management Institute.

[3] Demetris Koutsoyiannis, D. K. (1998). A mathematical framework for studying rainfall Demetris Koutsoyiannis*, Demosthenes Kozonis, Alexandros Manetas. Elsivier, Journal of Hydrology.
[4] El-Sayed, E. A. (2011). Generation of Rainfall Intensity Duration Frequency Curves For Ungauged Sites. Nile Basin Water Science \& Engineering Journal, 112.

[5] Elsebaie, I. H. (2011). Developing rainfall intensity-durationfrequency relationship for two regions in Saudi Arabia. Riyadh: Journal of King Saud University - Engineering Sciences.

[6] Hamaamin, Y. A. (2017). Developing of Rainfall IntensityDuration-Frequency Model for Sulaimani City. Journal of Zankoy Sulaimani.

[7] Koutsoyiannis. (1992). A Nonlinear Disaggregation Method With a Reduced Parameter Set for Simulation of Hydrologic Series. Water Resources Research.

[8] Koutsoyiannis, D. (2003). RAINFALL DISAGGREGATION METHODS: THEORY AND APPLICATIONS. Workshop on Statistical and Mathematical Methods for Hydrological Analysis, Rome.

[9] Monjo, R. (2016). Measure of rainfall time structure using the dimensionless $n$-index.

[10] Panagiotis Kossieris, C. M. (2016). A rainfall disaggregation scheme for sub-hourly time scales: Coupling a Bartlett-Lewis based model with adjusting procedures. Journal of Hydrology.

[11] Thein, S. H. (2019). Modelling of Short Duration Rainfall IDF Equation for Sagaing Region. American Scientific Research Journal for Engineering, Technology, and Sciences (ASRJETS).

[12] University, C. S. (n.d.). Intensity-Duration-Frequency (IDF) Curves. Hydrologic Science and Engineering.

[13] WHEATER, C. O. (1994). Improved fitting of the BartlettLewis Rectangular Pulse Model for hourly rainfall,. Hydrological Sciences Journal, 663-680. 